\title{
Interfacial Structure Control and 3D X-ray Imaging of Epoxy Monolith Bonding System with Surface Modification
}

\author{
Nanako Sakata, ${ }^{1}$ Yoshihiro Takeda, ${ }^{2}$ Masaru Kotera, ${ }^{3}$ Yasuhito Suzuki, ${ }^{1}$ and Akikazu Matsumoto ${ }^{1,}{ }^{*}$ \\ ${ }^{1}$ Department of Applied Chemistry, Graduate School of Engineering, Osaka Prefecture University, 1-1, \\ Gakuen-cho, Naka-ku, Sakai, Osaka 599-8531, Japan \\ ${ }^{2}$ Core Technology Research Department, X-ray Research Laboratory, Rigaku Corporation, 3-9-12, \\ Matsubara-cho, Akishima, Tokyo 196-8666, Japan \\ ${ }^{3}$ R\&D Department, HOTMELT ADHESIVE Division, MORESCO Corporation, 5-5-3, Minatojimaminami- \\ machi, Chuo-ku, Kobe, Hyogo 650-0047, Japan. \\ * Correspondence to Akikazu Matsumoto, Tel: +81-72-254-9292, Fax: +81-72-254-9292, \\ E-mail: matsumoto@chem.osakafu-u.ac.jp
}

\section{Contents}

Table S1. Water Contact Angles of Glass Surfaces modified with APS under Various Conditions

Table S2. Water Contact Angles of Glass Surfaces Modified with GPS under Various Conditions

Table S3. Water Contact Angles of Glass Surfaces modified with OS under Various Conditions

Table S4. Water Contact Angles and Surface Free Energies Determined for the Glasses with and without Surface Modification Using Coupling Agents

Table S5. Surface Free Energy of Surface-Modified Substrates with Silane Coupling Agents

Table S6. Surface Free Energy of AEDP-Modified SUS Determined under Various AEDP Concentration

Table S7. Effect of Thermal Welding Temperature on Bond Strength for Monolith Bonding of Cu and PET

Table S8. Surface Free Energies Determined for Glass and Metal Substrates Modified with Various Coupling Agents

Figure S1. Illustrative representation of the samples used for single lap-shear tensile test with (a) glass and (b) metal plates.

Figure S2. SEM images of the cross sections for the epoxy monolith prepared on a glass plate modified with APS under various conditions; the APS concentration was 1 or $3 \mathrm{wt} \%$ and the immersion time was 10,20 , or 30 min.

Figure S3. SEM images of the cross sections for the epoxy monolith prepared on a glass plate modified with GPS under various conditions; the GPS concentration was $0.25,0.5$, or 1 wt $\%$ and 
the immersion time was 5 or $10 \mathrm{~min}$.

Figure S4. Manual peeling test of the epoxy monoliths prepared on the glass plates modified with various coupling agents: (a) APS, (b) GPS, (c) AEDP (on the SUS plate), (d) MPS, (e) OS, and (f) untreated. The epoxy monolith on the glass modified with APS was tightly fixed and difficult to be peeled off.

Figure S5. X-ray tomograms constructed by computed tomography from the data of the epoxy monolith prepared on the custom-made glass stage after surface modification with APS. (a) Selected horizontal cross-sections for the entire monolith and (b) horizontal cross-sections near the interface between the monolith and the substrate at each $0.62-\mu \mathrm{m}$ depth for the area of 172.98-177.94 $\mu \mathrm{m}$ from the surface.

Figure S6. Cross-section images of the epoxy monolith prepared on the GPS-modified glass plate.

Figure S7. SEM images of the cross sections for the monolith bonding specimen of the GPSmodified glass substrate and PET. A large part of glass was exfoliated from the monolith when the samples were prepared by crash on cooling.

Figure S8. (a) 3D X-ray CT image the monolith bonding specimen of the GPS-modified glass substrate and PET, (b) cross-sectional image at the red plane in (a), and (c) cross-sectional image at the green plane in (a). The tilt angle of the plane for (c) was $2.5^{\circ}$ against the boundary of the PET and monolith layers.

Figure S9. SEM and optical microscope images of the fracture surfaces of the test pieces used for a tensile test (glass substrate side). Almost no monolith remained on the glass surface after fracture (interfacial fracture) when no modification was performed for the glass substrate. For the APS- and GPS modified samples, cohesive fracture was observed. A thin monolith layer remained on the glass substrates.

Figure S10. Stress-strain curves for the single-lap shear tensile test of the monolith bonding test pieces using (a) APS- and (b) GPS-modified glass substrates and PET. The tensile rate was 1.0 $\mathrm{mm} / \mathrm{min}$. The bonding area was $10 \mathrm{~mm} \times 10 \mathrm{~mm}$.

Figure S11. Stress-strain curves for the single-lap shear tensile test of the monolith bonding test pieces using (a) APS- and (b) GPS-modified SUS substrates and PET. The tensile rate was 1.0 $\mathrm{mm} / \mathrm{min}$. The bonding area was $10 \mathrm{~mm} \times 10 \mathrm{~mm}$.

Figure S12. SEM images of the cross sections for the epoxy monolith prepared on metal plates after surface modification.

Movies for the representation of the cross sections of the epoxy monolith prepared on the APSmodified glass plate. 
Table S1. Water Contact Angles of Glass Surfaces modified with APS under Various Conditions

\begin{tabular}{cccc}
\hline \multirow{2}{*}{ APS concentration (wt\%) } & \multicolumn{3}{c}{ Immersion time (min) } \\
\cline { 2 - 4 } & 10 & 20 & 30 \\
\hline 1.0 & $62.2 \pm 4.6$ & $65.8 \pm 1.5$ & $62.9 \pm 3.2$ \\
3.0 & $61.6 \pm 2.1$ & $65.2 \pm 0.9$ & $60.9 \pm 1.9$ \\
\hline
\end{tabular}

Table S2. Water Contact Angles of Glass Surfaces Modified with GPS under Various Conditions

\begin{tabular}{ccc}
\hline \multirow{2}{*}{ GPS concentration (wt\%) } & \multicolumn{2}{c}{ Immersion time (min) } \\
\cline { 2 - 3 } & 5 & 10 \\
\hline 0.25 & $45.5 \pm 5.7$ & $52.7 \pm 11.3$ \\
0.5 & $55.5 \pm 26.3$ & $59.3 \pm 4.6$ \\
1.0 & $30.0 \pm 22.2$ & $59.2 \pm 5.3$ \\
\hline
\end{tabular}

Table S3. Water Contact Angles of Glass Surfaces modified with OS under Various Conditions

\begin{tabular}{cccc}
\hline \multirow{2}{*}{ OS concentration (wt\%) } & \multicolumn{3}{c}{ Immersion time (min) } \\
\cline { 2 - 4 } & 1 & 5 & 10 \\
\hline 0.25 & $54.3 \pm 8.2$ & $44.4 \pm 1.6$ & $55.3 \pm 1.8$ \\
0.5 & $65.7 \pm 5.3$ & $58.3 \pm 2.5$ & $61.7 \pm 3.7$ \\
1.0 & $57.6 \pm 4.4$ & $53.4 \pm 4.1$ & $56.0 \pm 2.0$ \\
\hline
\end{tabular}

Table S4. Water Contact Angles and Surface Free Energies Determined for the Glasses with and without Surface Modification Using Coupling Agents

\begin{tabular}{lcc}
\hline coupling agent & water contact angle $(\mathrm{deg})$ & surface free energy $\left(\mathrm{mJ} / \mathrm{m}^{2}\right)$ \\
\hline None & $21.6 \pm 2.8$ & $310^{a}, 275^{b}, 72.8^{c}, 59.0^{d}$ \\
APS & $62.2 \pm 4.6$ & 24.6 \\
GPS & $59.2 \pm 5.3$ & 39.1 \\
MPS & $64.1 \pm 1.1$ & 20.6 \\
OS & $56.0 \pm 2.0$ & 22.3 \\
\hline
\end{tabular}

${ }^{a}$ Cited from Rhee, S. K. Surface energies of silicate glasses calculated from their wettability data. J. Mater. Sci. 1977, 12, 823-824. ${ }^{b}$ Cited from Olsen, D. A.; Osteraas, A. J. The critical surface tension of glass. J. Phys. Chem. 1964, 68, 2730-2732. ' Cited from Janczuk, N.; Bialopiotrowicz, T.; Dawidowicz, E. C. A.; Kliszcz, A. Determination of porous glass surface free energy components from contact angles. J. Mater. Sci. 1990, 25, 1682-1685. ${ }^{d}$ Cited from Stalder, A. F.; Kulik, G.; Sage, D.; Barbieri, L.; Hoffmann, P. A snake-based approach to accurate determination of both contact points and contact angles. Colloid Surf. A 2006, 286, 92-103. 
Table S5. Surface Free Energy of Surface-Modified Substrates with Silane Coupling Agents ${ }^{a}$

\begin{tabular}{|c|c|c|c|c|c|c|c|}
\hline & \multicolumn{4}{|c|}{ glass } & \multicolumn{2}{|c|}{ SUS } & \multirow{2}{*}{$\frac{\mathrm{Mg}}{\mathrm{GPS}}$} \\
\hline & GPS & APS & MPS & OS & $\mathrm{GPS}^{b}$ & $\mathrm{APS}^{b}$ & \\
\hline surface free energy $\left(\mathrm{mJ} / \mathrm{mm}^{2}\right)$ & 37.4 & 24.6 & 20.6 & 22.3 & 25.8 & 27.2 & 29.8 \\
\hline $\begin{array}{c}r^{2} \text { value } \\
\text { (coefficient of determination) }\end{array}$ & 0.94 & 0.96 & 0.97 & 0.85 & 0.97 & 0.99 & 0.92 \\
\hline
\end{tabular}

${ }^{a}$ Determined by Zisman's plot. ${ }^{b} 3$ wt $\%$ solution was used.

Table S6. Surface Free Energy of AEDP-Modified SUS Determined under Various AEDP Concentration ${ }^{a}$

\begin{tabular}{ccccc} 
AEDP concentration $^{b}(\mathrm{wt} \%)$ & 0.1 & 1.0 & 2.0 & 5.0 \\
\hline $\begin{array}{c}\text { surface free energy }\left(\mathrm{mJ} / \mathrm{mm}^{2}\right) \\
\begin{array}{c}r^{2} \text { value } \\
\text { (coefficient of determination) }\end{array}\end{array}$ & 9.5 & 15.7 & 18.8 & 16.8 \\
\hline
\end{tabular}

${ }^{a}$ Determined by Zisman's plot. ${ }^{b}$ Immersion time $20 \mathrm{~min}$.

Table S7. Effect of Thermal Welding Temperature on Bond Strength for Monolith Bonding of Cu and PET ${ }^{a}$

\begin{tabular}{cccc}
\hline \multicolumn{2}{c}{ conditions for thermal welding of PET } & sample number & bond strength \\
temperature $\left({ }^{\circ} \mathrm{C}\right)$ & time $(\mathrm{sec})$ & $\mathrm{N}$ & $(\mathrm{MPa})$ \\
\hline 140 & 150 & 3 & $4.87 \pm 0.60$ \\
150 & 150 & 5 & $4.82 \pm 0.34$ \\
160 & 150 & 5 & $4.73 \pm 0.53$ \\
\hline
\end{tabular}

${ }^{a}$ The Cu plate was modified with GPS.

Table S8. Surface Free Energies Determined for Glass and Metal Substrates Modified with Various Coupling Agents

\begin{tabular}{ccc}
\hline substrate & coupling agent & surface free energy $\left(\mathrm{mJ} / \mathrm{m}^{2}\right)$ \\
\hline glass & APS & 24.6 \\
glass & GPS & 39.1 \\
SUS & APS & 27.2 \\
SUS & GPS & 25.8 \\
SUS & AEDP & 17.1 \\
Mg & GPS & 29.8 \\
\hline
\end{tabular}



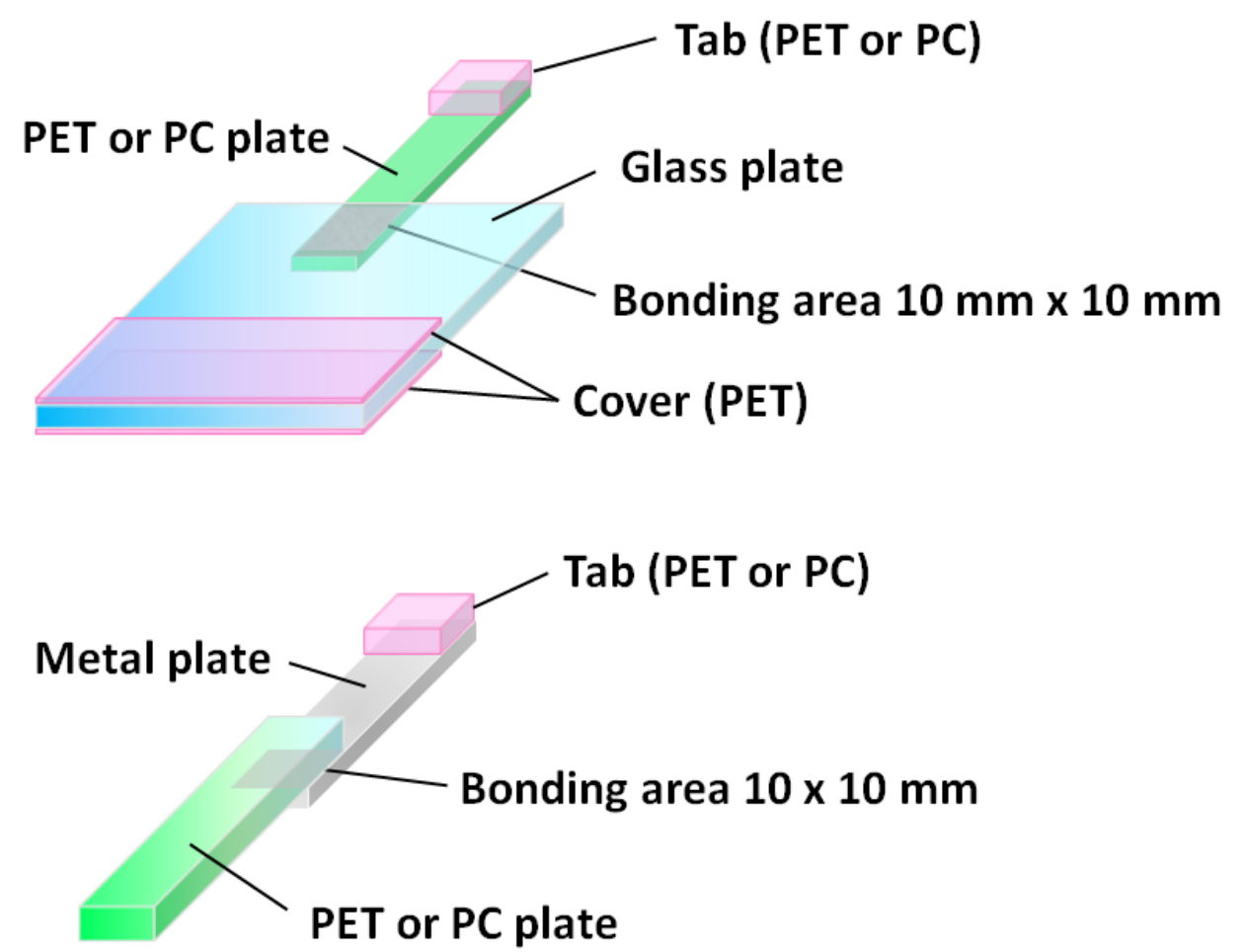

Figure S1. Illustrative representation of the samples used for single lap-shear tensile test with (a) glass and (b) metal plates. 

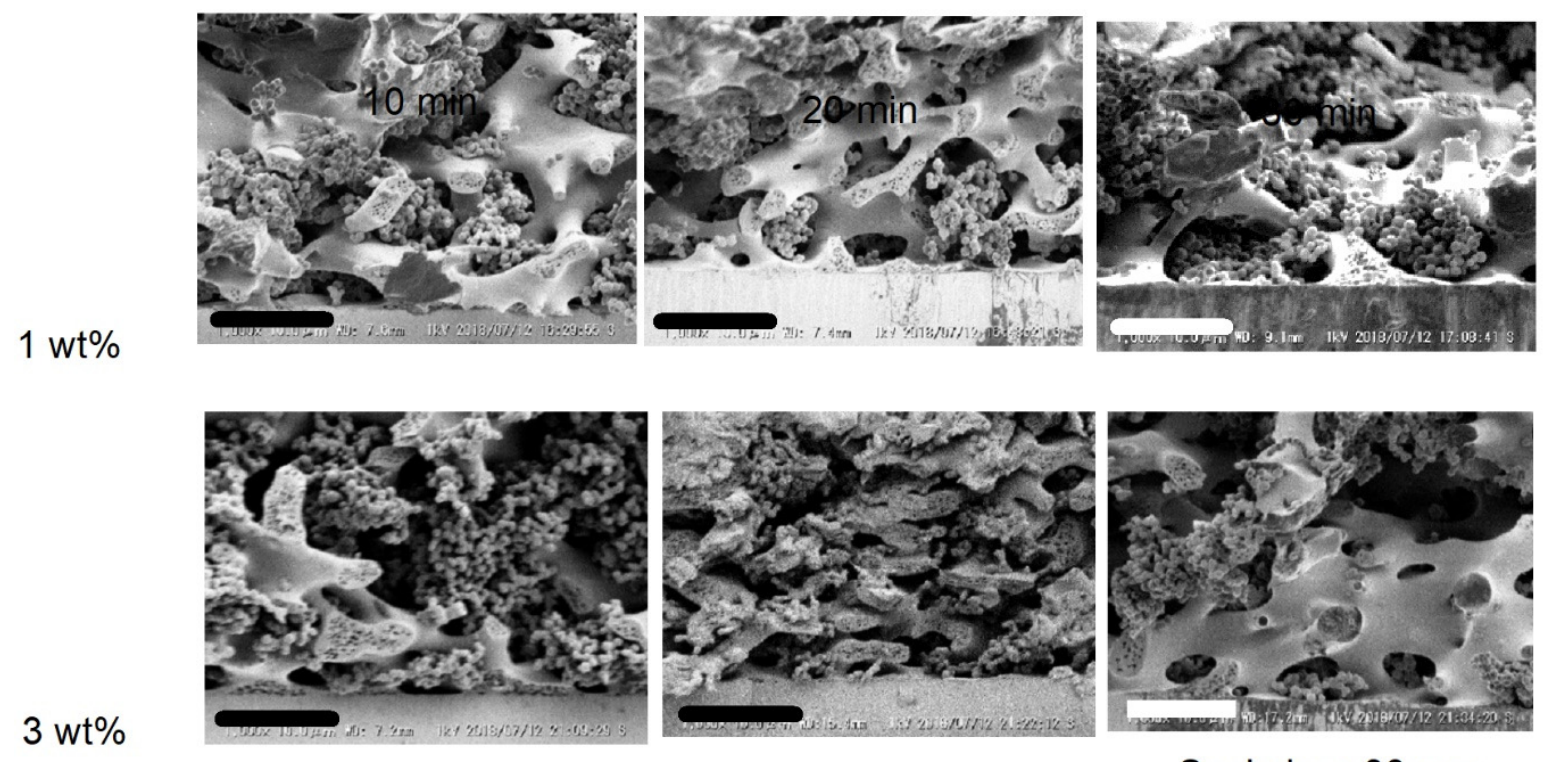

Scale bar: $30 \mu \mathrm{m}$

Figure S2. SEM images of the cross sections for the epoxy monolith prepared on a glass plate modified with APS under various conditions; the APS concentration was 1 or 3 wt\% and the immersion time was 10,20 , or 30 min. 

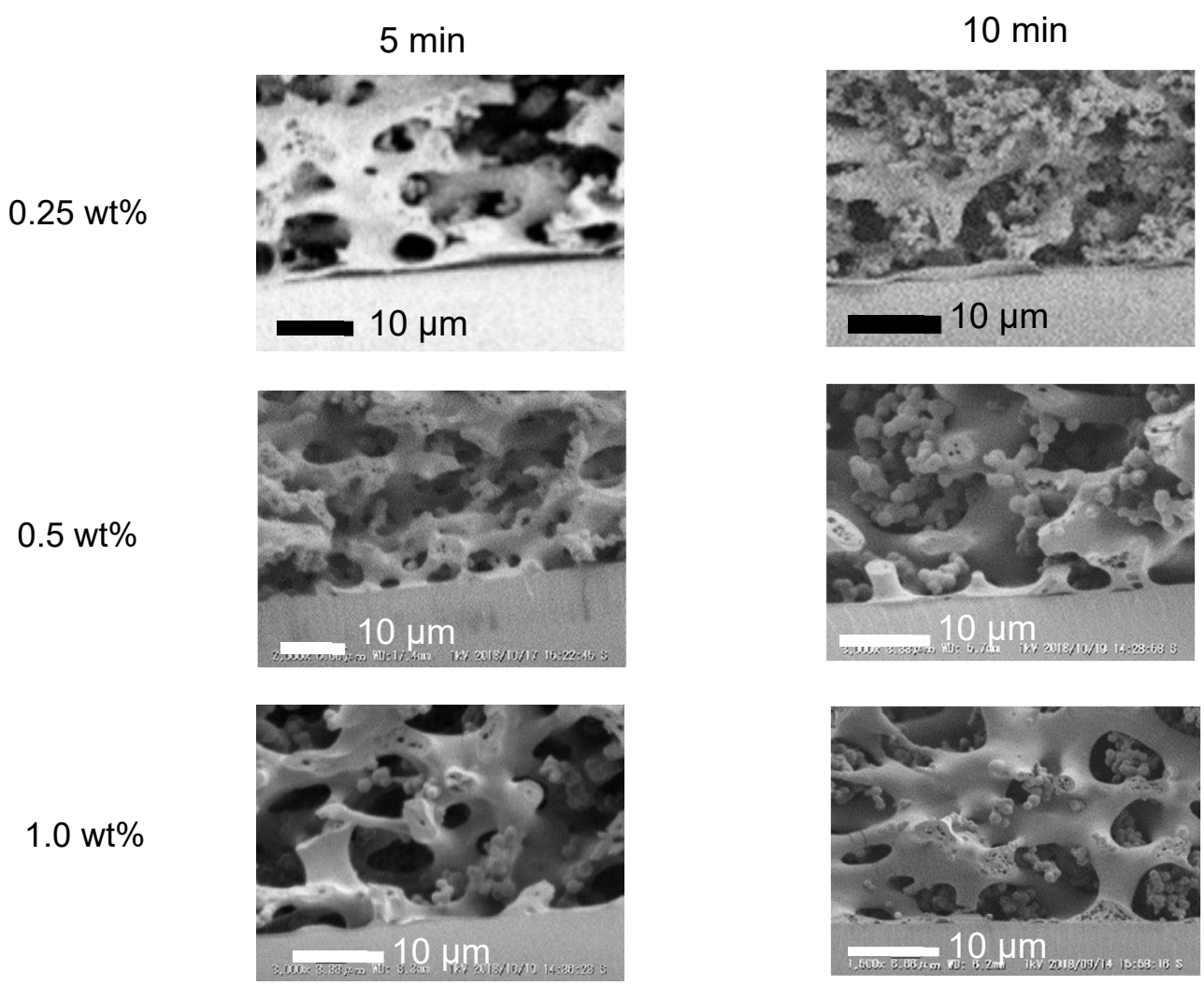

Figure S3. SEM images of the cross sections for the epoxy monolith prepared on a glass plate modified with GPS under various conditions; the GPS concentration was $0.25,0.5$, or $1 \mathrm{wt} \%$ and the immersion time was 5 or $10 \mathrm{~min}$. 
(a)

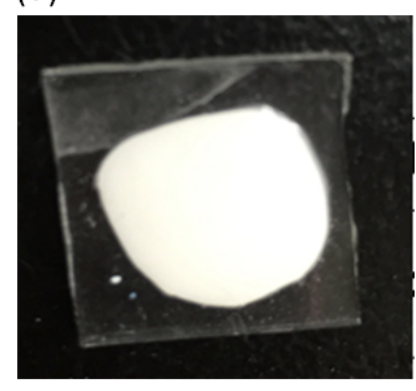

(d)

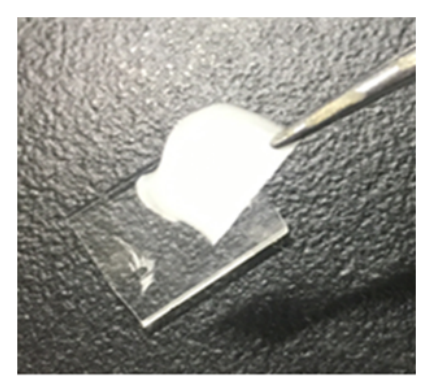

(b)

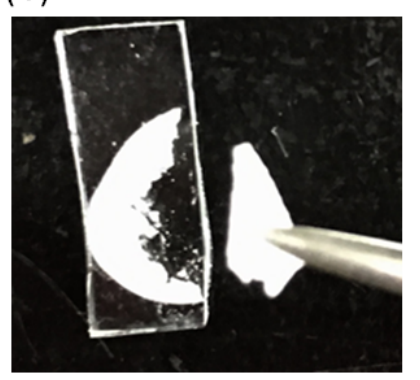

(e)

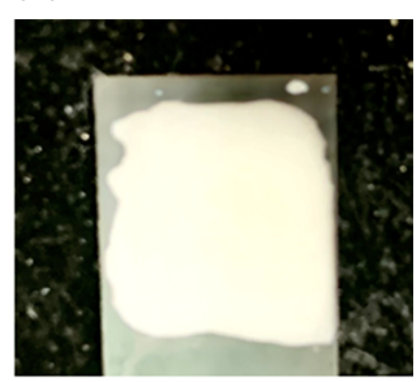

(c)

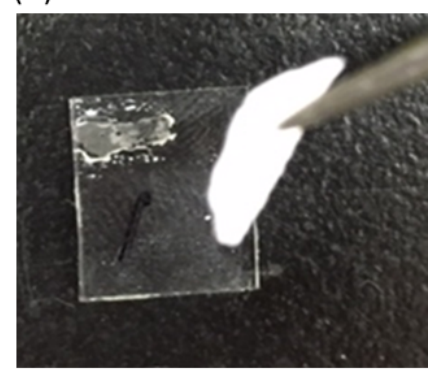

Figure S4. Manual peeling test of the epoxy monoliths prepared on the glass plates modified with various coupling agents: (a) APS, (b) MPS, (c) OS, (d) untreated, and (e) AEDP (on the SUS plate). The epoxy monolith on the glass modified with APS was tightly fixed and difficult to be peeled off. 

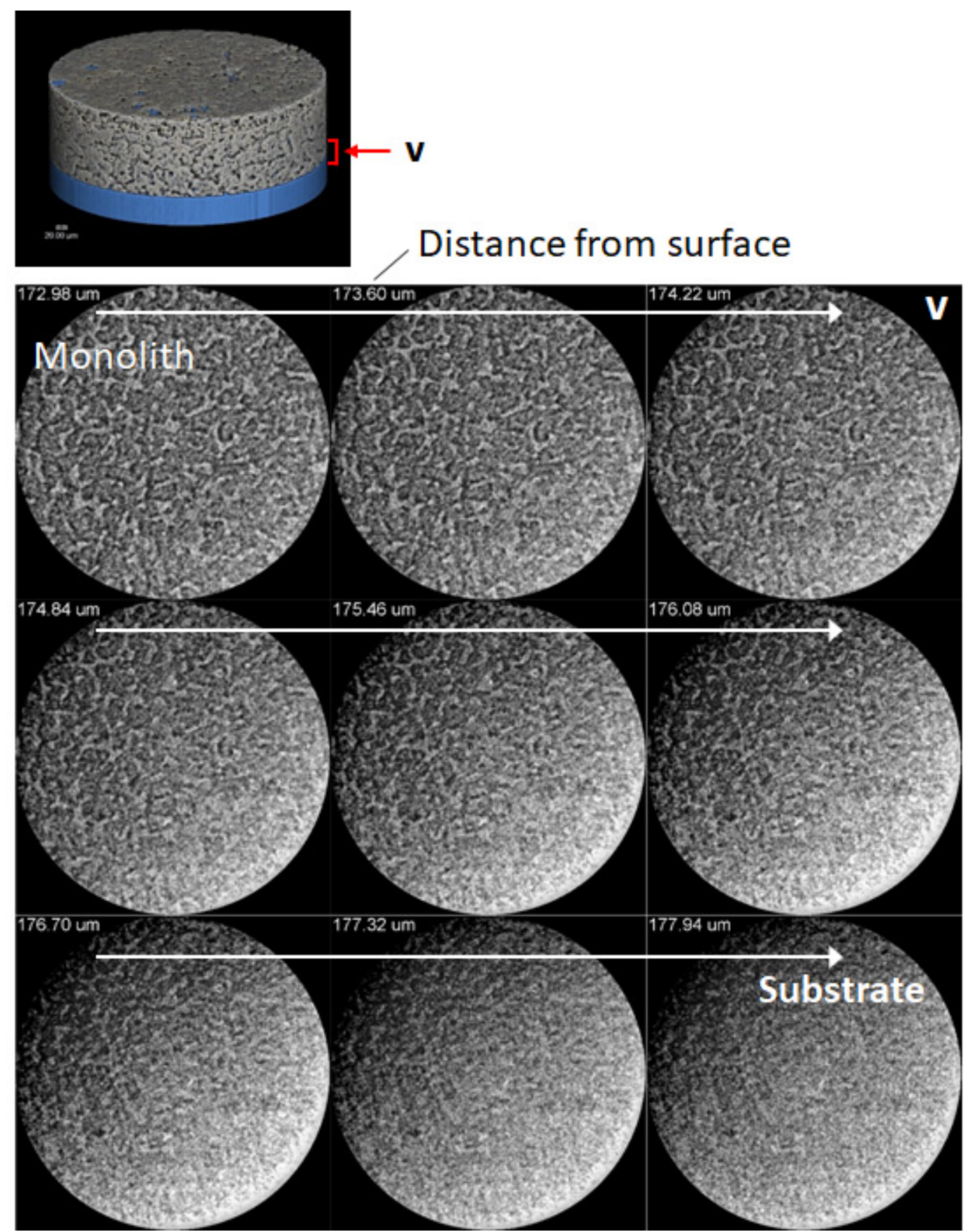

Figure S5. X-ray tomograms constructed by computed tomography from the data of the epoxy monolith prepared on the custom-made glass stage after surface modification with APS. Horizontal cross-sections near the interface between the monolith and the substrate at each 0.62- $\mu \mathrm{m}$ depth for the area of 172.98-177.94 $\mu \mathrm{m}$ from the surface. 


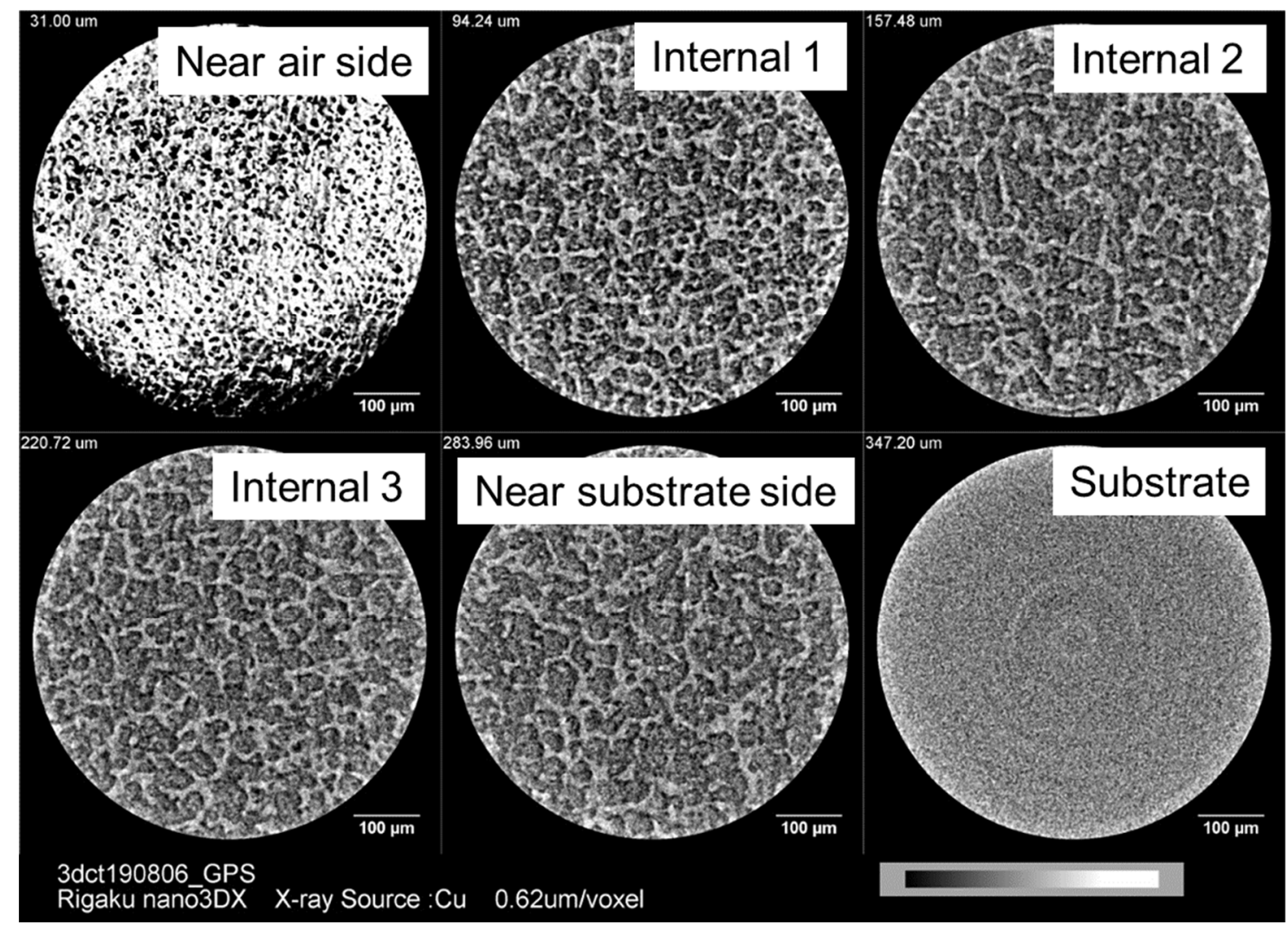

Figure S6. Cross-section images of the epoxy monolith prepared on the GPS-modified glass plate. The images were constructed from the X-ray transmission images obtained by X-ray CT measurement. The images of "Internals 1 to 3 " and "near substrate side" were for the area of $94.24,157.48,220.72$, and $283.96 \mathrm{~mm}$ from the top of the monolith, respectively. 

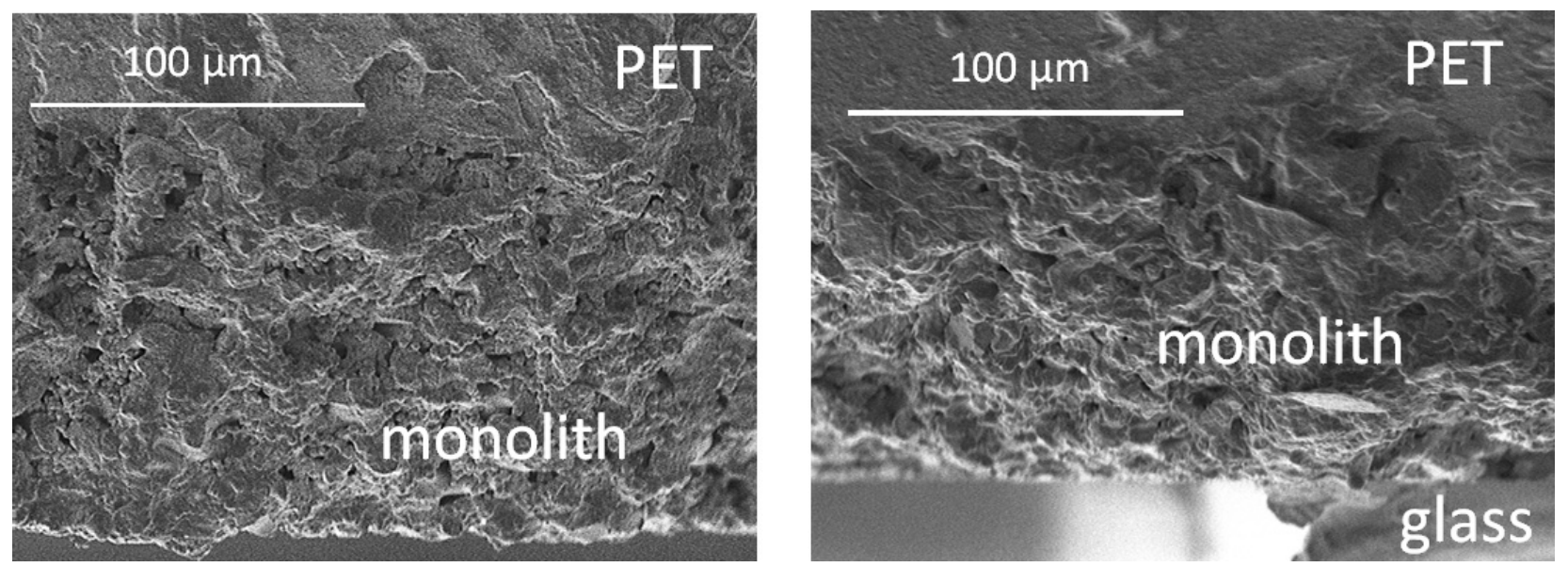

Figure S7. SEM images of the cross sections for the monolith bonding specimen of the GPSmodified glass substrate and PET. A large part of glass was exfoliated from the monolith when the samples were prepared by crash on cooling. 
(a)

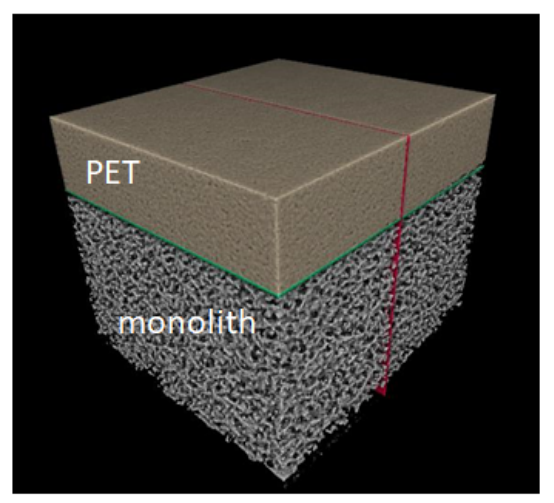

(b)

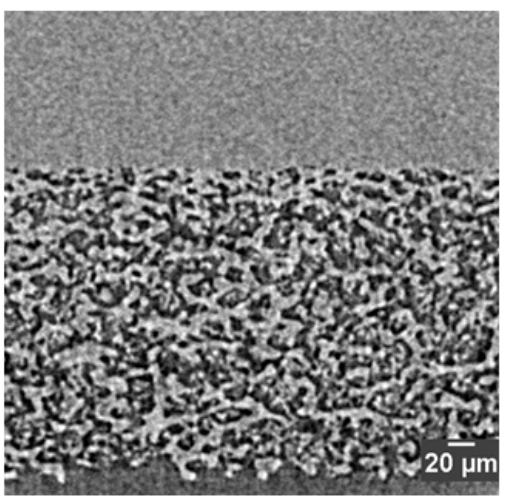

(c)

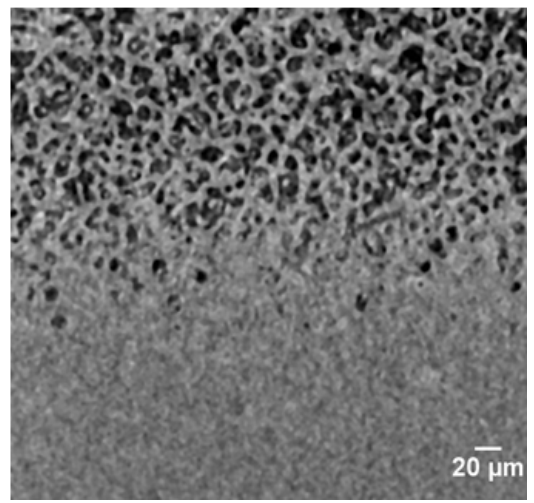

Figure S8. (a) 3D X-ray CT image the monolith bonding specimen of the GPS-modified glass substrate and PET, (b) cross-sectional image at the red plane in (a), and (c) cross-sectional image at the green plane in (a). The tilt angle of the plane was $2.5^{\circ}$ against the boundary of the PET and monolith layers. 


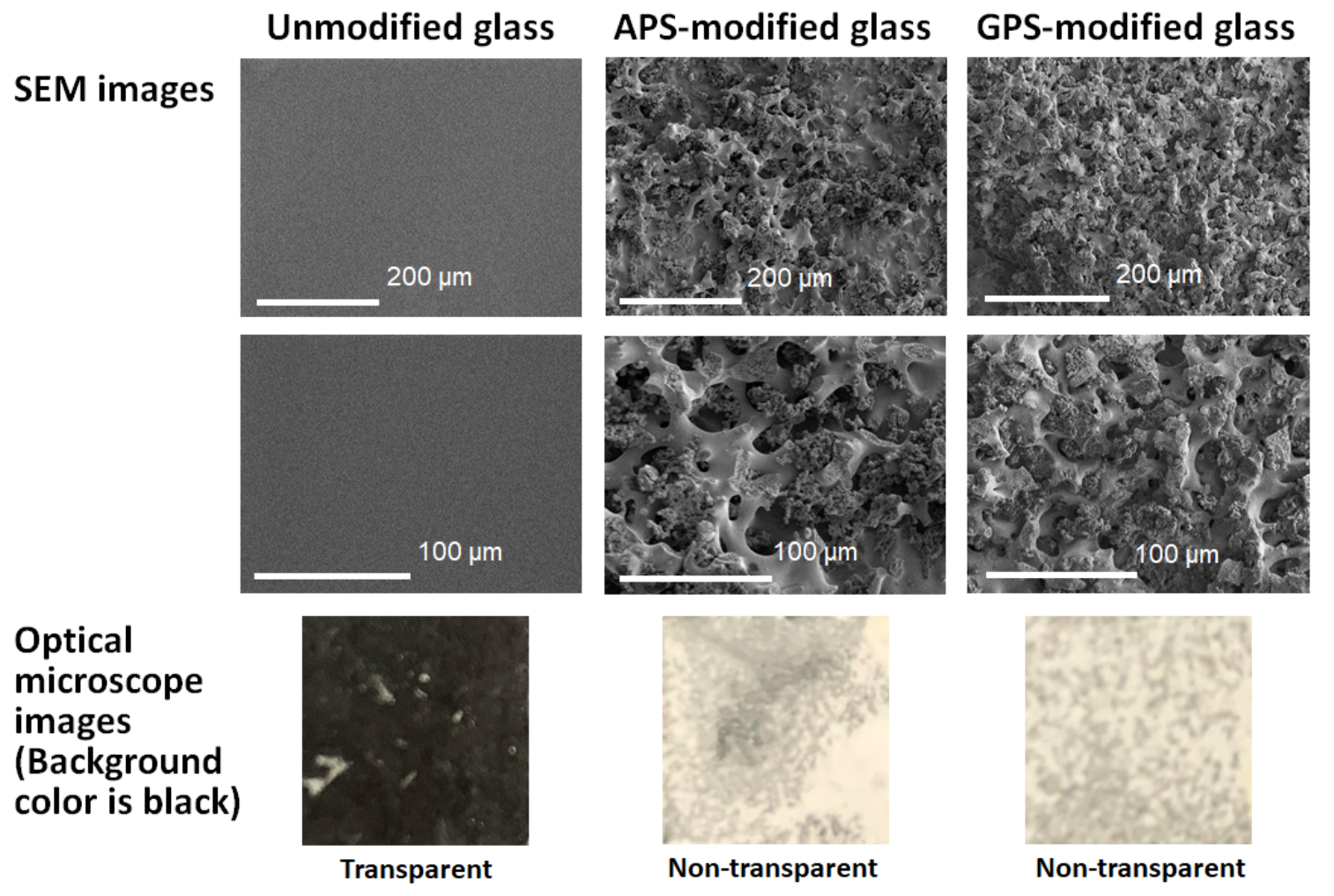

Figure S9. SEM and optical microscope images of the fracture surfaces of the test pieces used for a tensile test (glass substrate side). Almost no monolith remained on the glass surface after fracture (interfacial fracture) when no modification was performed for the glass substrate. For the APS- and GPS modified samples, cohesive fracture was observed. A thin monolith layer remained on the glass substrates. 
(a)

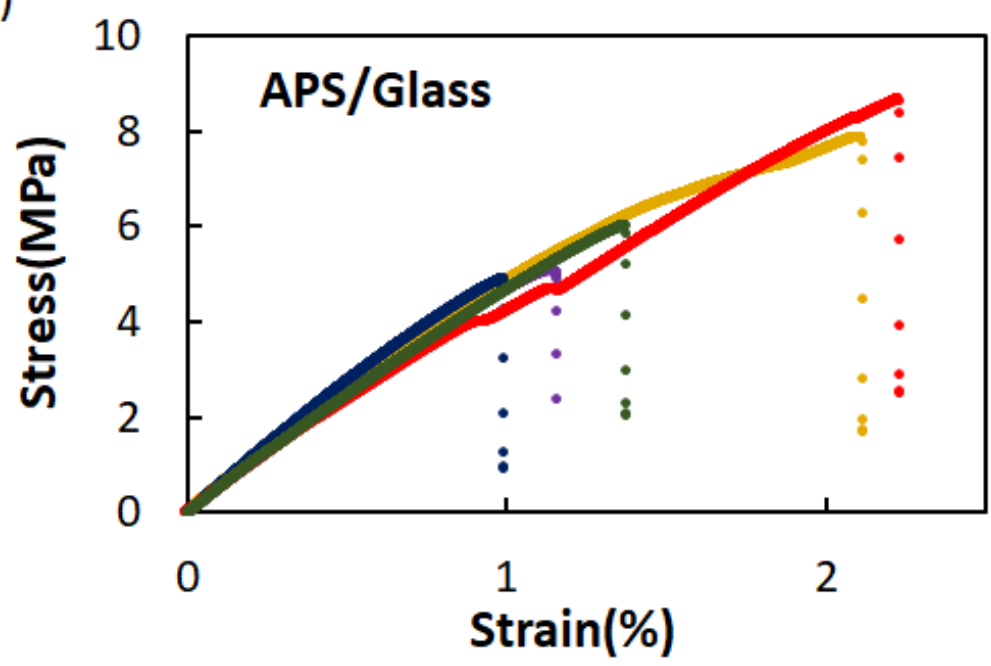

(b)

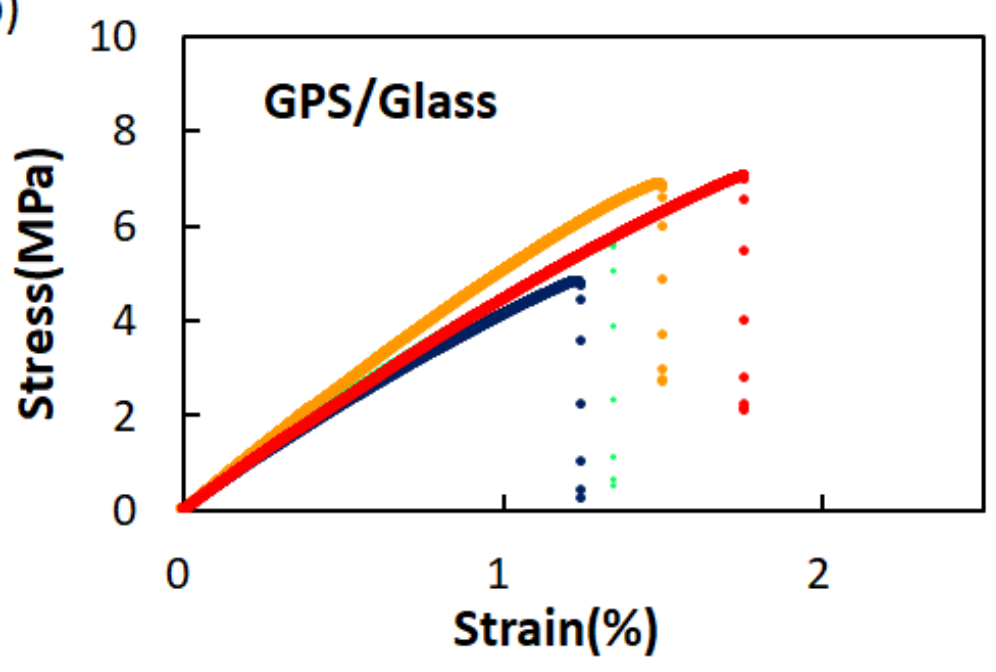

Figure S10. Stress-strain curves for the single-lap shear tensile test of the monolith bonding test pieces using (a) APS- and (b) GPS-modified glass substrates and PET. The tensile rate was 1.0 $\mathrm{mm} / \mathrm{min}$. The bonding area was $10 \mathrm{~mm} \times 10 \mathrm{~mm}$. 

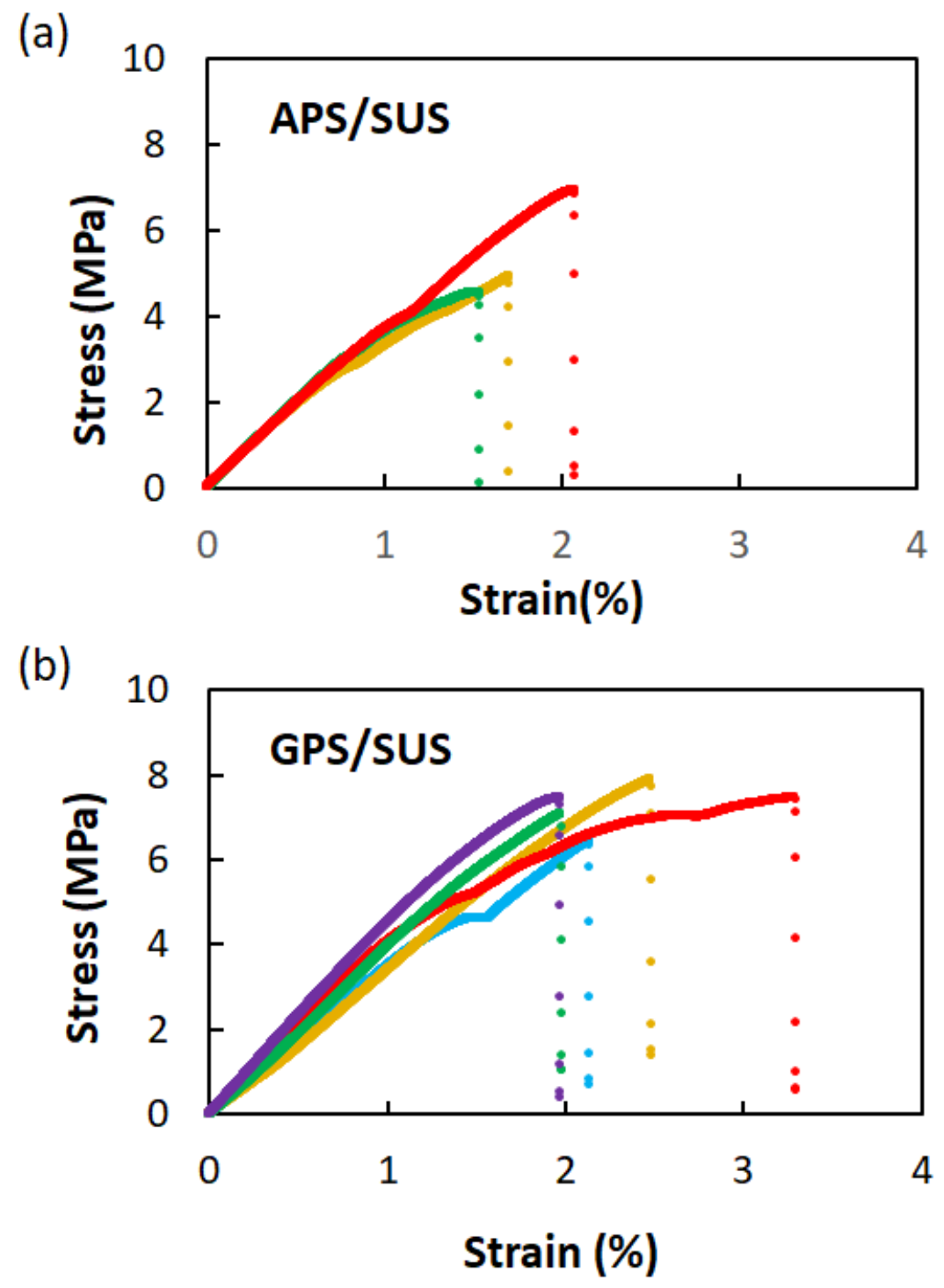

Figure S11. Stress-strain curves for the single-lap shear tensile test of the monolith bonding test pieces using (a) APS- and (b) GPS-modified glass substrates and PET. The tensile rate was 1.0 $\mathrm{mm} / \mathrm{min}$. The bonding area was $10 \mathrm{~mm} \times 10 \mathrm{~mm}$. 
(a)

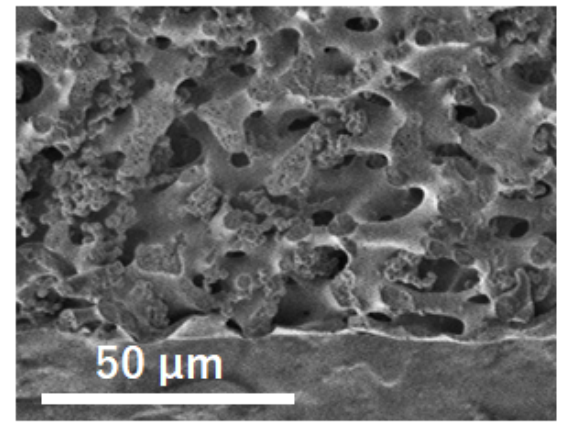

(c)

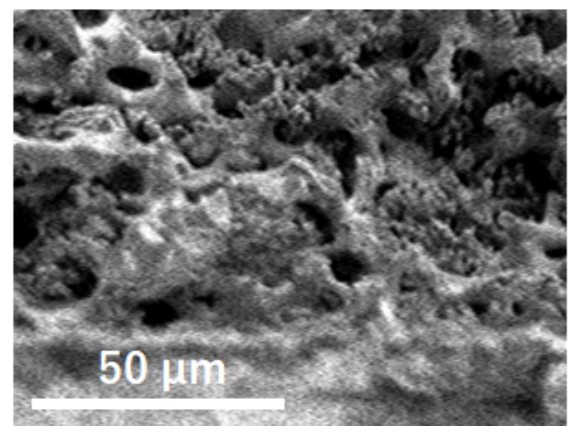

(b)

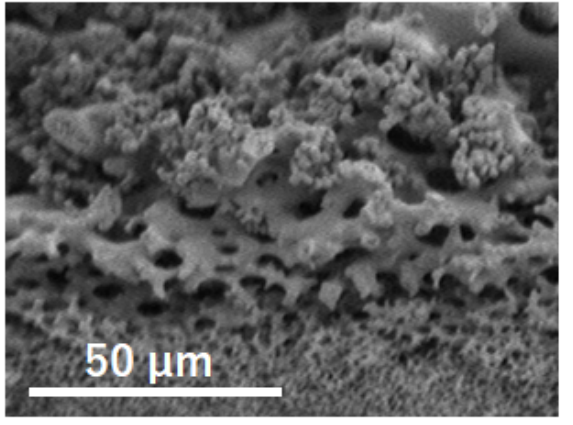

(d)

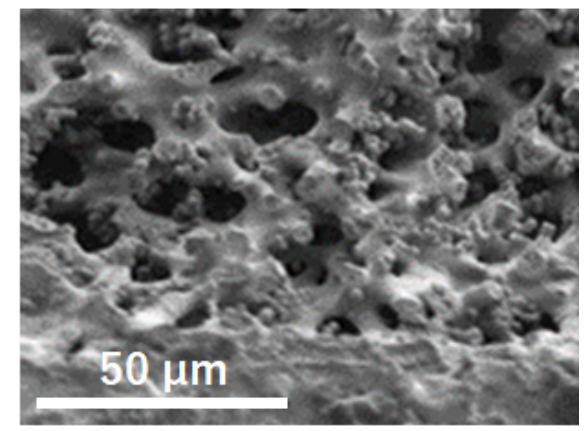

Figure S12. SEM images of the cross sections for the epoxy monolith prepared on metal plates after surface modification. 
Movies for the representation of the cross sections of the epoxy monolith prepared on the APSmodified glass plate. 